\title{
MAPEAMENTO DE FEIÇÕES MORFOLÓGICAS DA PLANÍCIE DE INUNDAÇÃO DO ALTO RIO PARANÁ, ATRAVÉS DO USO DE PRODUTOS ORBITAIS
}

\author{
Ismar Renan Alves de Andrade \\ Grupo de Estudos Multidisciplinares do Ambiente - GEMA /UEM - Av. Colombo, 5.790 - Jd. Universitário - Maringá - \\ Paraná - Brasil -CEP 87.020-900-e-mail: ismar84@gmail.com \\ Edvard Elias de Souza-Filho \\ Grupo de Estudos Multidisciplinares do Ambiente - GEMA /UEM - Programa de Pós-graduação em Geografia \\ - Universidade Estadual de Maringá/UEM - Av. Colombo, 5.790 - Jd. Universitário - Maringá - Paraná - Brasil - \\ CEP87.020-900-e-mail: edvardmarilia@wnet.com.br
}

\begin{abstract}
Resumo
Os estudos em planícies de inundação muitas vezes são obstaculizados pelas dificuldades de acesso comuns a esses ambientes. Neste trabalho foi realizado o mapeamento das feições morfológicas da Planície de Inundação do Alto Rio Paraná, através do uso de produtos de eensoriamento remoto (Modelo Digital de Elevação e imagens orbitais). O emprego das técnicas de sensoriamento remoto permitiu realizar satisfatoriamente o mapeamento das feições morfológicas (paleocanais, baixios e alagadiços, crevasses, paleodiques) inclusive nas áreas de acesso mais difícil.
\end{abstract}

Palavras chave: Planície de inundação; sensoriamento remoto; feições morfológicas.

\begin{abstract}
The studies in floodplains many times are hindered by the access difficulties common to those environments. In this paper, the mapping of Upper Paraná River Floodplain morphological features was accomplished by using Remote Sensing products (Digital Elevation Model and orbital images). The use of Remote Sensing techniques allowed to accomplish satisfactorily the mapping of the morphological features besides in areas of difficult access
\end{abstract}

Keywords: Floodplains; digital elevation model; morphological features.

\section{Introdução}

Planícies de inundação são formas oriundas da ação fluvial e podem ter definições diferentes de acordo com o enfoque do estudo. Para Nanson e Croke (1992), em sua classificação genética, trata-se de uma forma aluvial, separada de seu canal por margens e construída por sedimentos transportados pelo rio. Para esses autores, tendo em vista a perspectiva geomórfica, as planícies de inundação são melhor categorizadas geneticamente, em função da sua inter-relação entre os processos referentes ao rio e à planície que eles constróem.
Os estudos de grandes áreas normalmente são onerosos, uma vez que exigem grande apoio logístico e de pessoal. As dificuldades de acesso e deslocamento aumentam quando se trata de planícies de inundação, uma vez que os problemas transcendem à extensão da área, somando-se a elas as presenças de terrenos alagados, lagoas e vegetação densa ou espinhenta a ser transposta (COMUNELLO, 2001).

A alternativa cada vez mais usada para se transpor os obstáculos naturais ao tratar-se desse tipo de am- 
biente é o Sensoriamento Remoto. Uma série de autores contribuíram significativamente no tocante ao uso de sistemas sensores em estudos ambientais. Smith (1997); Merters (2002) fazem considerações acerca do uso de tais ferramentas na avaliação de sistemas fluviais e na determinação de áreas inundáveis por meio de uma série de variáveis observáveis em produtos do sensoriamento remoto.

O trabalho de Townsend e Walsh (1998) busca, através da construção de um MDE (Modelo Digital de Elevação) e sua associação com imagens de satélite Landsat (TM), fazer a modelagem de uma planície de inundação. Para os autores, os MDE's oriundos de radares são uma saída eficaz para a realização de inferências a respeito de áreas onde os dados são escassos. Além disso, são lembrados também os problemas com custos e logística quando se trabalha em áreas amplas.

Os trabalhos de Oliveira (2005) e de Fuckner et al. (2009) avaliam a qualidade dos Modelos Digitais de Elevação disponíveis (ASTER, RADARSAT, SRTM). Para estes autores, o MDE ASTER apresenta uma boa qualificação para distintas áreas, podendo ainda ser melhorado quando associado a uma boa gama de pontos de controle.

Considerando as dificuldades de acesso e a escassez de dados cartográficos, este trabalho teve como objetivo gerar uma carta de feições morfológicas para a Planície de Inundação do Alto Rio Paraná, através do uso de produtos de Sensoriamento Remoto, (modelo digital de elevação e imagens orbitais). Pretende-se que esses produtos possam servir como base para o entendimento dos processos que ocorrem na planície, tais como a dinâmica de inundação e a evolução das formas.

A unidade de estudo localiza-se na Planície de Inundação do Alto Rio Paraná, mais precisamente na região de Porto Rico e compreende a área situada na margem esquerda do Rio Paraná, entre a Foz do Rio Paranapanema e a primeira Foz do Rio Ivinheima (Canal Ipoitã). (Figura 1). As localidades mais próximas são a cidade de Porto Rico e o distrito de Porto São José, no lado paranaense. E, no lado sul-mato-grossense, as comunidades distam mais de 15 quilômetros da margem do rio (SOUZA FILHO e STEVAUX, 2004).

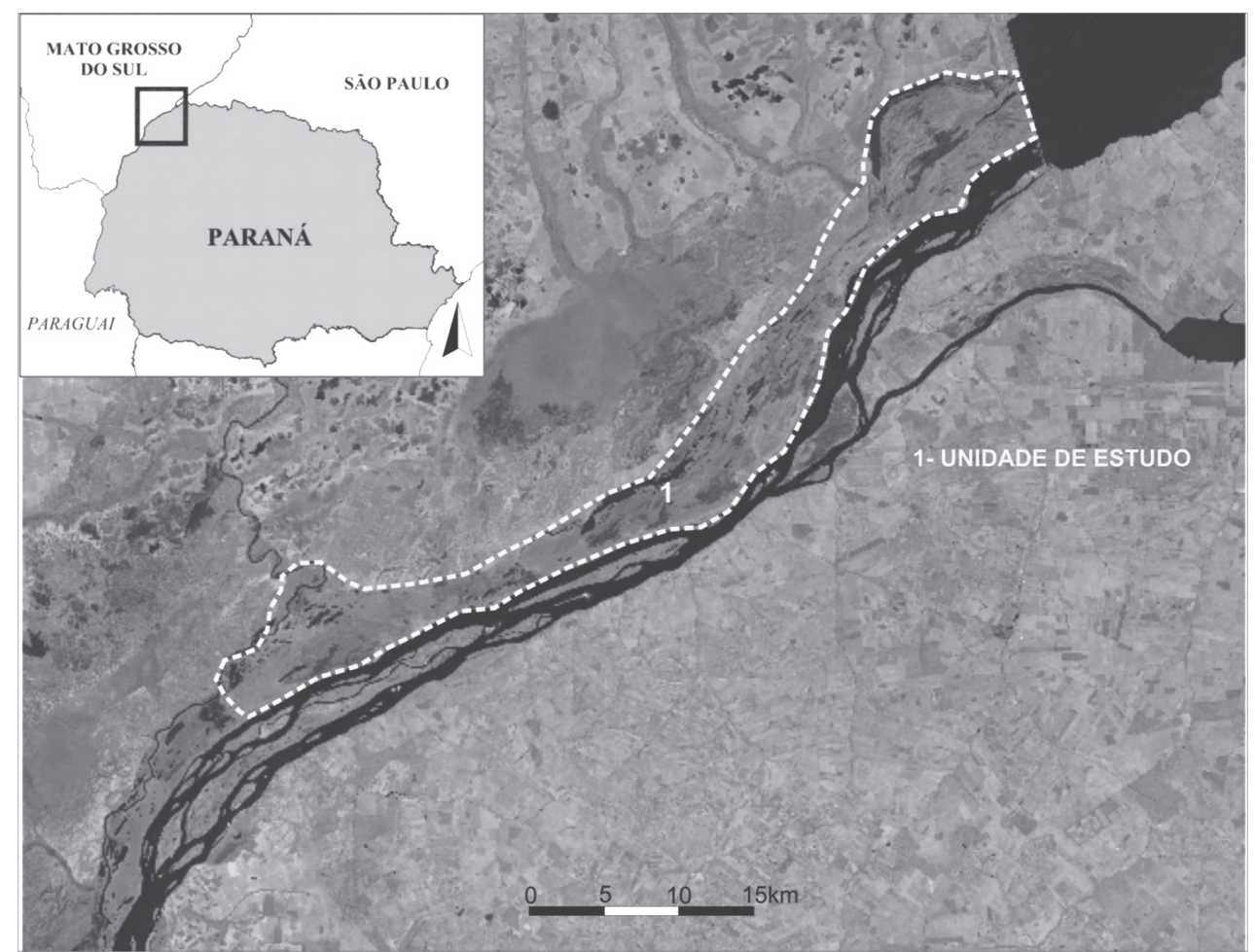

Figura 1 - Delimitação da unidade de estudos, planície de inundação do Alto Rio Paraná, na tríplice fronteira entre os estados de MS, PR e SP. A montante observa-se os reservatórios de Porto Primavera e Rosana. 


\section{Metodologia}

Para a realização do proposto para este estudo, foram utilizados produtos de Sensoriamento Remoto (imagens orbitais ASTER e CBERS HRC), que foram tratados para extração de informação dos mesmos. Os produtos foram associados às informações coletadas em campo.

O ASTER é um sensor que está a bordo do satélite Terra, lançado pela NASA em dezembro de 1999 (Abrams e Hook, 2001). Este sensor possui três subsistemas que possibilitam a variação da resolução espacial conforme a faixa de comprimento de onda (VNIR, SWIR e TIR), além de possuir o recurso de visada inclinada na mesma órbita, que permite obter imagens estereoscópicas na banda 3 , situada na região do infravermelho próximo.

As bandas com visada lateral (3B e $3 \mathrm{~N}$ ) permitem que sejam gerados dois tipos de MDE: o relativo (sem pontos de controle para ajuste altimétrico) e o absoluto (o usuário precisa fornecer pontos de controle). Para os fins desse estudo será criado um MDE relativo, uma vez que o que se pretende é a identificação de formas, altimetria relativa das mesmas em relação às morfologias adjacentes e não o seu valor altimétrico absoluto.

Para geração do Modelo Digital de Elevação relativo ASTER foram utilizadas duas cenas para recobrir a área de estudos. O procedimento foi realizado utilizando a ferramenta AsterDTM ${ }^{\circledR}$, no software ENVI. O procedimento para a extração do DEM relativo das cenas está detalhadamente descrito em Sulsoft (2005).

O mapa de feições morfológicass completo da área de estudo foi gerado a partir de uma classificação não supervisionada (unsupervised classification) (LILLESAND e KIEFER, 1994), das imagens orbitais ASTER, utilizando as bandas 1, 2 e 3 do sensor VNIR. Nesta operação são agrupados na imagem os pixels de valores similares, em classes determinadas de acordo com os parâmetros oferecidos ao software. O sensor VNIR, com resolução espacial de 15 metros, permitiu realizar a identificação das formas em escala geral.

A acurácia da classificação foi testada por meio da elaboração do índice Kappa. (PONZONI e ALMEIDA, 2007), em que:

$$
\hat{K}=\frac{N \sum_{i=1}^{k} x_{i}-\sum_{i=1}^{k}\left(x_{i+} \cdot x_{+i}\right)}{N^{2}-\sum_{i=1}^{k}\left(x_{i+} . x_{+i}\right)}
$$

onde: $\hat{K}$ : valor estimado Kappa; $k$ : número de linhas; $x_{\ddot{i}}$ : número de observações na linha $i$ e coluna $i ; \sum_{i=1}^{k} x_{i \ddot{i}}$ : soma dos elementos da matriz em sua diagonal principal; $x_{i+}$ : soma total das observações para as linhas; ${ }^{x_{+i}}$ : soma total das observações para as colunas; $N$ : número de observações totais.

Para tanto, foi verificada a concordância dos dados de campo com os da classificação através de uma tabulação cruzada dos mesmos. O cruzamento dos dados de campo com as classes geradas, Landis e Koch (1977) estabelecem limiares do índice Kappa, para avaliar a classificação.

A câmera HRC está a bordo do satélite CBERS 2B e opera numa única faixa espectral, produz imagens de uma faixa de 27 quilômetros de largura com uma resolução de $2,5 \mathrm{~m}$, que permite a observação com grande detalhamento dos objetos da superfície (Rodrigues et al., 2009). Nesses produtos foi realizada a classificação das formas da planície com base nos seus aspectos visuais e espaciais. $\mathrm{O}$ sensor HRC permitiu a identificação das formas da planície em escala de detalhe.

Foram realizadas duas missões em campo, nas quais foram visitados 45 pontos. Em cada um dos pontos foram observadas características que pudessem classificar altimetria relativa, presença ou ausência de vegetação, proximidade com o canal principal do Rio Paraná.

\section{Resultados}

A associação dos produtos de Sensoriamento Remoto às observações realizadas em campo permitiu identificar e classificar os diferentes tipos de feições ocorrentes na planície, como será mostrado a seguir. A Figura 2 mostra uma área da planície à jusante da UHE de Porto Primavera. Nesse ponto podem ser observados conjuntos de formas que puderam ser identificados visualmente nas cenas HRC. O Modelo Digital de Elevação possibilitou a classificação das formas em classes de acordo com suas características altimétricas. A Figura 3 mostra alguns perfis traçados na planície sobre o MDE, ficando clara a diferenciação altimétrica entre as formas, tornando possível agrupá-las considerando este critério.

Como parte final desse estudo, foi elaborada uma carta de feições morfológicas da planície (figura 4), onde foram identificadas e classificadas as distintas formas que ocorrem na área. A classificação utilizou os critérios de altimetria, tipo de vegetação, presença ou ausência de água, forma da feição, e posicionamento na planície. 


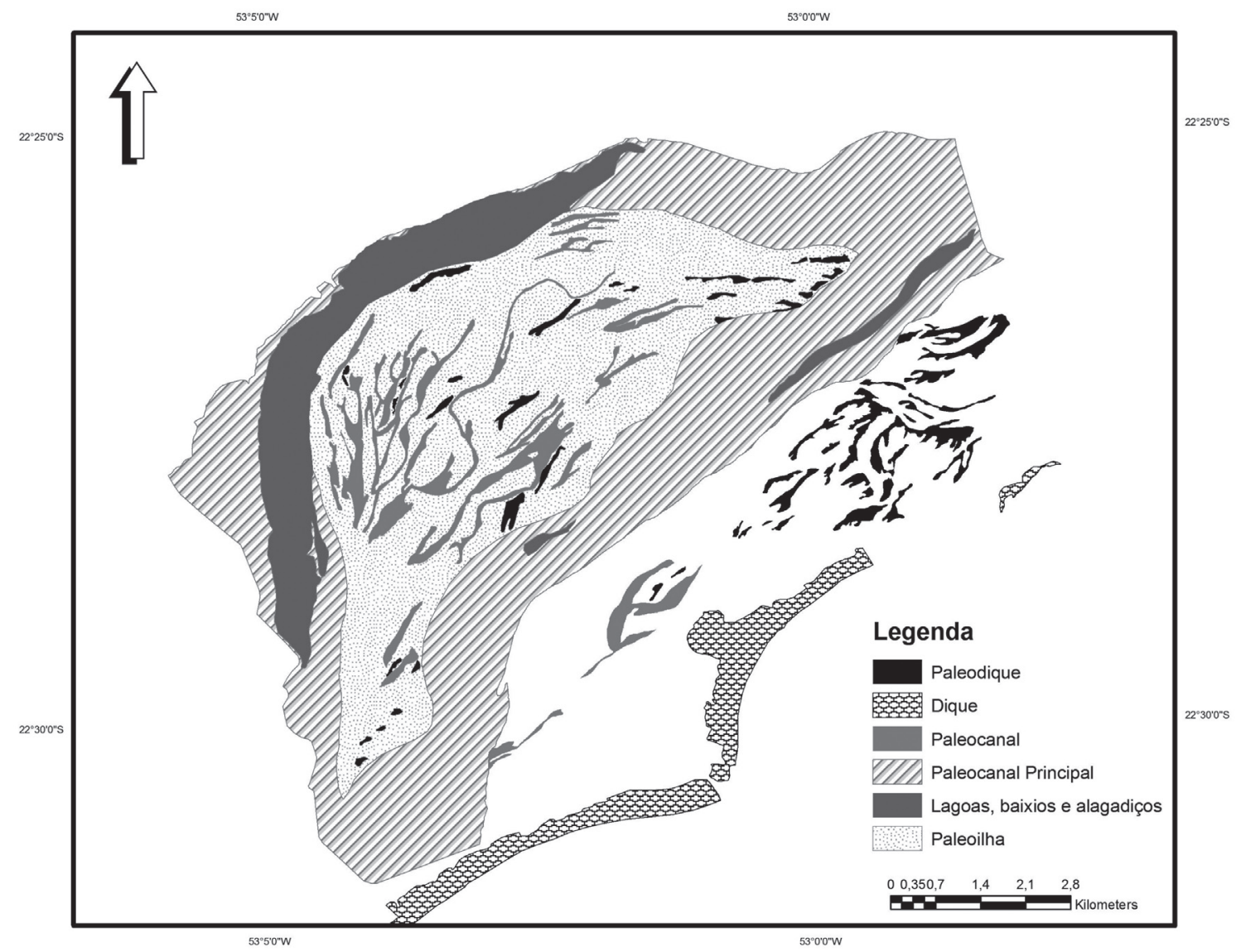

Figura 2 - Classificação detalhada das formas de planície. Na região logalizada imediatamente à jusante da UHE de Porto Primavera, foram identifcadas diferentes feições morfológicas que se sobrepõem.
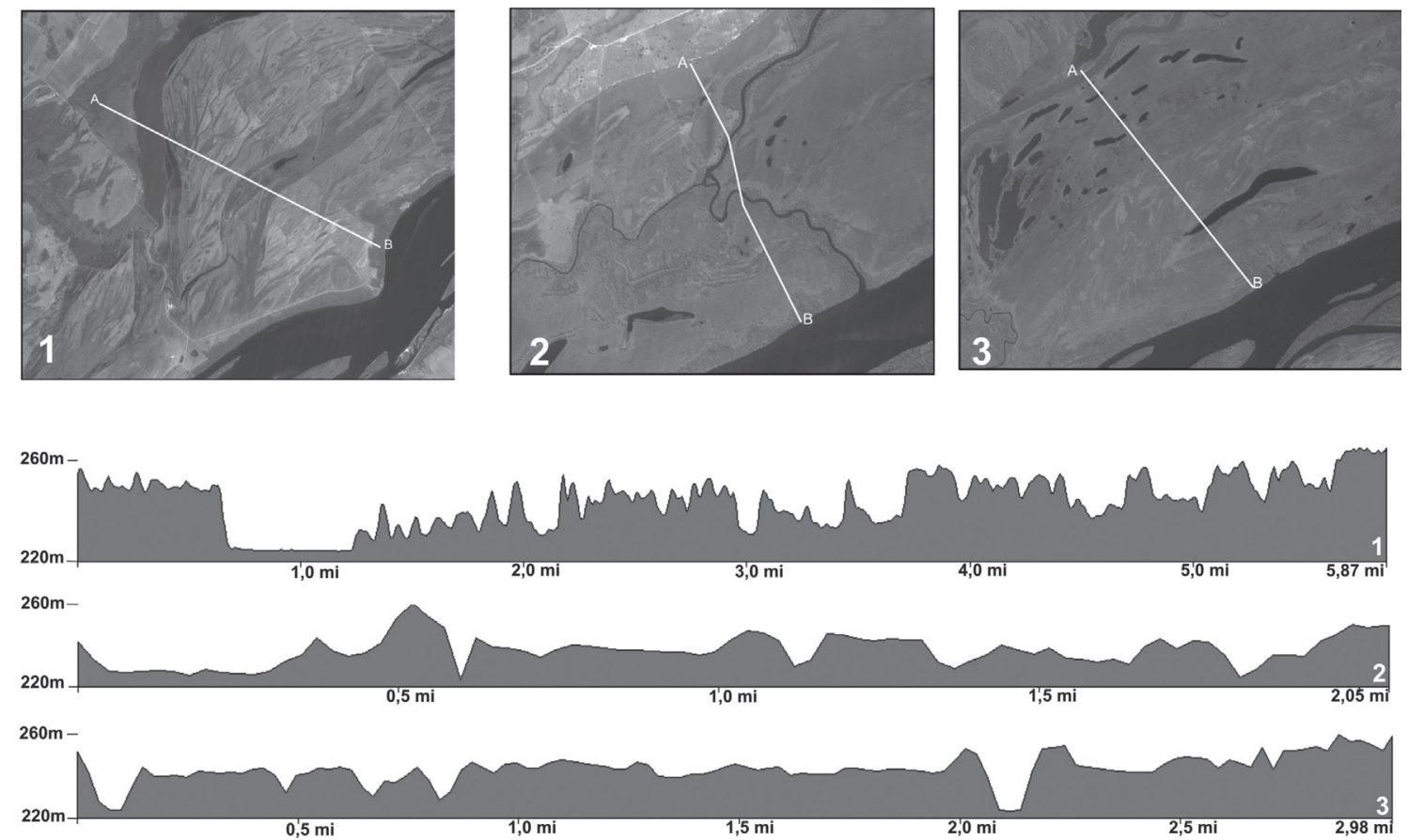

Figura 3 - Perfis altimétricos traçados em diferentes partes da planície. É possivel observar nos perfis as diferentes morfologias ocorrentes ao longo da planície, destacando-se as áreas onde ocorrem canais atuais, paleocanais e diques marginais. 
Na elaboração da carta de feições morfológicas da planície foram utilizados todos os produtos gerados posteriormente (MDE's, imagem ASTER, imagens CBERS HRC), além das observações realizadas em campo. As diferentes feições foram agrupadas em seis grupos de classes diferentes, que representam os diferentes subambientes da planície e sua descrição está apresentada a seguir:

Diques marginais/Vegetação arbórea: foram agrupadas esses dois tipos de feições, pois as mesmas se confundem ao longo da área. Dentro da planície, os únicos locais de ocorrência concentrada de vegetação arbórea são os diques marginais, em função de sua posição altimétrica mais elevada. No interior da planície, os paleodiques margeiam canais inativos, mas, mesmo nestes casos, permitem o crescimento de vegetação arbórea.

Leques de rompimento de dique (Crevasses): ao longo da planície foram identificadas duas crevasses que puderam ser cartografadas devido às suas características particulares (proximidade do canal do Rio Paraná, formato em pata de ave, presença de areia, formação de pequenos canais). Em diversos outros pontos da planície o rompimento de diques marginais acusa a possível formação de crevasses, mas ainda sem forma características para que pudessem ser representadas em mapa.
Áreas intermediárias vegetadas: trata-se de áreas com altimetria menor que a dos diques marginais, porém maior que a dos baixios e alagadiços. Nessas áreas há predominância de vegetação de gramíneas e de arbustos, não diferenciáveis entre si devido à resolução das imagens. A vegetação arbórea pode existir, mas encontra-se restrita a agrupamentos localizados.

Areas intermediárias não vegetadas: são áreas que ocorrem na alta planície e são semelhantes às classificadas no item anterior, mas não apresentam vegetação natural porque estão sendo cultivadas. Encontram-se cortadas por drenos, que apesar de permitirem a retirada de água da planície não impedem a ocorrência de "brejos" ricos em matéria orgânica.

Baixios e alagadiços: são as áreas relativamente mais baixas na planície e permanecem a maior parte do tempo encharcadas de água. Nessa unidade, a ocorrência de lagoas é frequente. Não possuem forma bem definida e seus limites não são claros.

Paleocanais: eles são similares aos baixios e alagadiços em termos topográficos. Contudo, são facilmente identificados pela sua forma alongada e com margens bem definidas, marcadas pela presença de elevações com vegetação arbórea (paleodiques marginais) em suas margens.

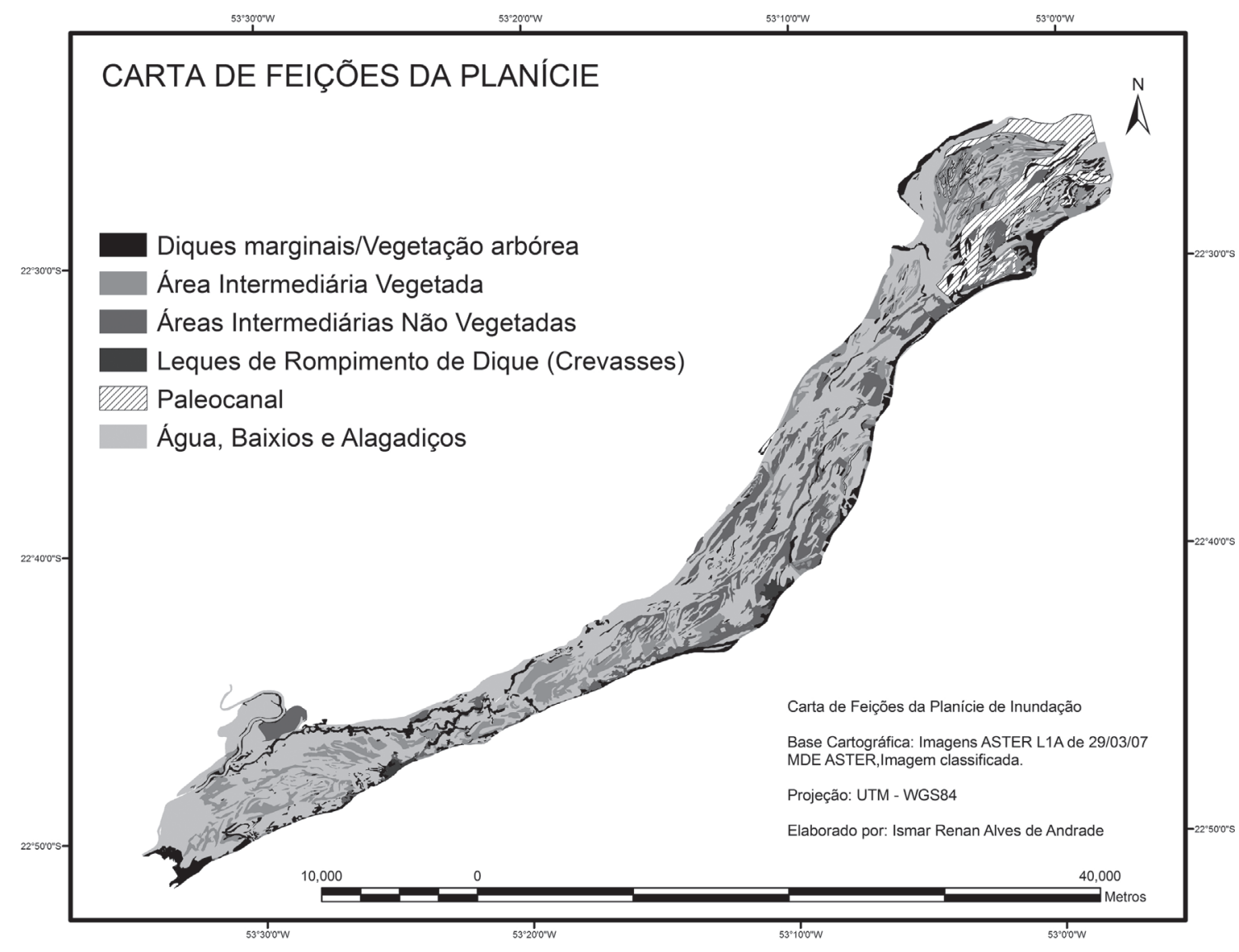

Figura 4 - Carta de feições morfológicas da planície de inundação. 


\section{Conclusões}

O emprego de técnicas de Sensoriamento Remoto para a identificação de formas de planície mostrou ser uma ferramenta bastante eficaz na identificação das morfologias em uma escala de maior e menor detalhe. A modelagem numérica do terreno foi eficiente e possibilitou a produção de produtos confiáveis, com resultados confirmados por verificação de campo.

Também é importante levar em consideração que as imagens ASTER possuem erros em seus valores altimétricos. A acurácia desses produtos deve ser avaliada estatisticamente, porém, neste trabalho essa análise não foi realizada por não estar no escopo do mesmo.

Apesar de não ser muito utilizada em planície de inundação, a classificação não supervisionada é uma técnica bastante eficaz também para este tipo de ambiente. A boa qualidade deste produto é expressa pela alta concordância entre as observações realizadas em campo e o produto gerado, baseando-se nos limiares do índice kappa de Landis e Koch (1977).

A reunião de todos os produtos permitiu que se elaborasse uma carta de formas de planície de maneira satisfatória. As dificuldades que antes existiam (falta de dados altimétricos e dificuldade de acesso) são hoje supridas pelos produtos existentes para a pesquisa, inclusive gratuitamente.

\section{Referências bibliográficas}

ABRAMS, M.; HOOK, S. ASTER user handbook. Version 2. Pasadena, Califórnia, CA: Jet Propulsion Laboratory/EROS Data Center, 2001.

COMUNELlO, E. Dinâmica de inundação de áreas sazonalmente alagáveis na planície aluvial do Alto Rio Paraná. Dissertação de Mestrado - UEM/PEA. Maringá/PR, 2001.

FUCKNER, M. A.; MORAES, E. C.; FLORENZANO, T. G. Processamento de dados multiespectrais termais aplicado à análise espaço-temporal dos padrões de temperatura da superfície nas Regiões Metropolitanas de São Paulo e Rio de Janeiro. In: Anais do XIV Simpósio Brasileiro de Sensoriamento Remoto. São José dos Campos (SP): Instituto Nacional de Pesquisas Espaciais 2009, p. 1369-76.

JUNK, W.J. BAYLEY, P.B.; SPARKS, R.E. The flood pulse concept in river-floodplain systems. In: Procedings of the International Large River Symposium. Can. Spec. Publ. Fish. Aquat. Sci. 106 p. 110-127, 1989.
LANDIS, J.R.; KOCH, G. G. The measurement of observer agreement for categorical data. Biometrics, v. 33, n. 1, p. 159-174, 1977.

LILLESAND, T.M; KIEFER, R. W. Remote sensing and image interpretation. 3. ed. Wiley, USA, 1994.

Merters, L.A.K. Remote sensing of riverine landscapes. In: Freshwater Biology 47: 799-816, 2002.

NANSON, G. C.; CROKE, J. C. A genetic classification of floodplain. Geomorphology, n.4, p.459-486, 1992.

OLIVEIRA, C. G. Avaliação de modelos digitais de elevação gerados a partir de sensores remotos orbitais ópticos (ASTER) e radar (RADARSAT-1, SRTM). 2005. 184p. Dissertação (Mestrado em Sensoriamento Remoto) - Instituto Nacional de Pesquisas Espaciais (INPE), São José dos Campos, 2005.

PONZONI, F. J.; ALMEIDA, E. S. A estimativa do parâmetro Kappa (k) da análise multivariada discreta no contexto de um SIG. In: Simpósio Brasileiro de Sensoriamento Remoto, 8, 1996, Salvador, Brasil. Anais. São José dos Campos, INPE, 1996. p. 729-733.

SMITH, L. C. Satellite remote sensing of river inundation area, stage, and discharge: a review. In: Hydrological Process 11: 1427-1439, 1997.

SOUZA FILHO, E. E. Aspectos da geologia e estratigrafia dos depósitos sedimentares do Rio Paraná entre Porto Primavera e Guaíra (MS). Tese de Doutoramento, Instituto de Geociências/ USP, São Paulo, 180p, 1993.

SOUZA FILHO, E. E. ; STEVAUX, J. C . Geomorphology of the Parana River Floodplain in reach between Paranapanema and Ivai Rivers. In: Ângelo Antonio Agostinho; Liliana Rodrigues; Luiz Carlos Gomes; Sidinei Magela Thomaz; Leandro E. Miranda. (Org.). Structure and functioning of the Paraná River and its floodplain. 1 ed. Maringá: EDUEM, 2004, v. 01, p. 09-13.

SteVAUX, J. C. The Upper Paraná River (Brazil): Geomorphology, Sedimentology and Paleoclimatology. In: Quaternary International. Vol 21. p. 143 - 161, 1994.

SULSOFT. AsterDTM 2.2: instalation \& user's guide. Porto Alegre: Sulsoft, 2005. 24p.

TOWNSEND, P. A; WALSH, S. J. Modeling floodplain inundation using a integrated GIS with radar and optical remote sensing. In: Geomorphology 21: 295-312, 1998. 